Western University Scholarship@Western

Centre for the Economic Analysis of Property

Centre for the Economic Analysis of Property

Rights Working Papers

Rights

1982

\title{
Monopolistic Competition and Multi-Product Brand Names
}

Stephen E. Margolis

Follow this and additional works at: https://ir.lib.uwo.ca/economicsceapr_wp

Part of the Economics Commons

Citation of this paper:

Margolis, Stephen E.. "Monopolistic Competition and Multi-Product Brand Names." Centre for the Economic Analysis of Property Rights Working Papers, 82-03. London, ON: Department of Economics, University of Western Ontario (1982). 
Working Paper Series

$82-03$

MONOPOLISTIC COMPETITION AND MULTI-

PRODUCT BRAND NAMES

by

Stephen E. Margolis*

Department of Economics

University of Western Ontario

Lond on

Canada

Ju1y 1982

* The author acknowledges helpful comments from Stan Liebowitz, John Palmer and Guy Bridgeman. Financial support was provided by The Canadian Ministry of Consumer and Corporate Affairs through The Centre for Economic Analysis of Property Rights at The University of Western Ontario.

Major funding for the Centre for Economic Analysis of Property Rights has been provided by The Bureau of Corporate Affairs, Consumer and Corporate Affairs, and by the Academic Development Fund, The University of Western Ontario. The views expressed by individuals associated with the Centre do not reflect official views of the Centre, The Bureau of Corporate Affairs, or The University of Western Ontario.

Subscriptions to the Workshop papers and the Working Paper Series are $\$ 40$ per year for institutions and $\$ 25$ per year for individuals. Individual copies, if available, may be purchased for $\$ 3$ each. Address all correspondence to John Palmer, Centre for Economic Analysis of Property Rights, The University of Western Ontario, London, Ontario, CANADA N6A 5C2 


\section{INTRODUCTION}

This paper considers the economic model of monopolistic competition in an enviromment in which firms find it profitable to promote more than one product under a single brand or firm name. When a firm advertises, promotes, provide quality, honors implicit contracts, and so on, it may succeed in creating a favorable reputation. Such reputation enhancement is presumably the major or only reason for these activities. Where the firm engages in promotional activities specifically related to one of its products, it is likely that the enhanced reputation spills over to other products provided by the firm. The existence of such interactions is shown here to modify the normative implications of monopolistic competition in a very fundamental way. In particular, the so called excess capacity theorem is shown not to hold under these circumstances.

There are many examples of brand names which serve several products. General Motors produces vehicles of virtually every description; Kellogg produces many different types of cereals; Canon sells calculators, cameras and copiers. In fact, unless products are defined rather broadly, it is difficult to come up with examples of brand names which are associated with single products. Many examples of multi-product firms arise as a consequence of production advantages in the traditional sense, and brand exploitation may reinforce the tendency toward joint production in those cases. However, there are examples of brand extension where traditional production advantages of joint production are hard to identify or are readily replaced by market transactions.

Throughout this paper, the term brand name is used to reflect any device which would identify the source of a product. Trade marks or trade names obviously serve this function. Firm names may or may not be used for 
this purpose. For example, Ford imports trucks manufactured in Japan by Toyo Kogo, but only the Ford identification and not Toyo Kogo is used to market these vehicles. Proctor and Gamble is a reasonably well recognized firm name, however, the emphasis in their advertising is on the trade names which it owns, such as Ivory and Tide. Less obvious firm identifiers are industrial designs, packaging formats and styling, or advertising formats. The discussion which follows pertains to any of these devices which provide a signal to the consumer regarding the firm which takes responsibility for the product.

The firm in monopolistic competition is assumed to have some control over the price of its output--it perceives a downward sloping demand curve--as a consequence of product differentiation. Consumers regard the product as being different in some way from other products, so that small price changes do not result in the firm capturing none or all of the market. This is the monopoly element in monopolistic competition and it has the famous implication that firms in monopolistic competition will experience excess capacity; they will not operate at the lowest possible average total cost.

In Chamberlin's original presentation of the theory of monopolistic competition, it is acknowledged that variety might well be valued by consumers, and that product differentiation might be worth its cost. Recent research in this area has presented hypothetical examples in which it could be shown that there was too much, too little, or just enough product differentiation vis a vis the variety-cost tradeoff. Although these exercises are anything but conclusive as to the extent of excess capacity, their popularity and concreteness threatens to establish the tradeoff as a fact of economic life which might be presumed to be a proper concern of public policy. There remains 
a legitimate question, however, as to whether there is an inevitable tradeoff between cost and variety. The recent literature has ignored a substantial body of discussion of the monopolistic competition model which accumulated in the 1950's and 60's. This literature addressed the model in a much more fundamental way, addressing both its internal coherence and empirical applicability. A key development in this debate was a reformulation by Demsetz [1959, 1964, 1968] which was answered in part by Barzel in 1970. The following builds in part on the work of Demsetz and Barzel and joins Demsetz in arguing that the tradeoff that has been proposed need not exist.

There are many sorts of policy implications of the original Chamberlin model, but the most pervasive and important is a general suspicion of product differentiation and the means of differentiating products, such as advertising, packaging, industrial design, trademarks and brand names. If such differentiating measures do not provide helpful information to consumers, yet do result in the inefficiency historically attributed to monopolistic competition, then public policies which project these institutions are misdirected. If these measures do provide useful information, it remains for us to evaluate their cost. The costliness attributed to these measures will depend upon our view of the functioning of markets which might be characterized as monopolistically competitive.

The paper is organized as follows. Section II briefly considers Demsetz' demonstration that the excess capacity theorem does not hold, and presents Barzel's objection to Demsetz. Section III presents some support for the idea of interaction of promotional efforts. Section IV presents a simple example of interaction of promotional efforts. Section $V$ is a fairly speculative discussion of rationalization and Section VI is a discussion of the implications of this work for public policy. 
Finally, it should be noted that this paper explicitly ignores the issue of the value of variety per se, an issue which has recently been the focus of some attention. Early critics noted that the variety offered by a monopolistically competitive industry might well justify the higher costs. Recent work (Spence 1976, Dixit and Stiglitz 1977) claims that the proper combination of variety and cost is achieved by markets only under extremely restricted conditions on consumer preferences and cost functions. While it 
should be granted that consumers probably do value diversity, this model, like that of Demsetz, suggests that there may not be any such compromise of variety and cost in monopolistically competitive equilibrium.

II. THE EXCESS CAPACITY THEOREM

This section considers briefly the original Demsetz contribution, which denied the necessity of excess capacity in monopolistic competition, and BarzeI's criticism of Demsetz' formulation. Readers thoroughly familiar with this exchange are urged to skip this section, as they will be offended by its simplicity.

Demsetz' reconsideration of monopolistic competition is based on the recognition that selling expense will be varied optimally as quantity is varied. Associated with each quantity that an entrepreneur could sell is a profit maximizing selling expense. Recognition of this yields an average revenue (demand) curve constructed under the assumption that advertising expense is adjusted optimally as quantity is changed. Demsetz refers to this curve as the mutatis mutandis average revenue (MAR) curve. There is, of course, a companion notion of a mutatis mutandis marginal revenue curve (MR) .

A plausible shape for the MAR curve is shown in Figure 1(a). Demsetz derives this shape under the assumption that advertising experiences initially increasing then decreasing returns to scale. Also shown in Figure $1(\mathrm{~b})$ is a mutatis mutandis average total cost curve such that the industry has achieved an "efficient" equilibrium. The average cost curve reflects average cost so as to include advertising expenses. As Demsetz

2 To avoid awkward expression, the term advertising has been used throughout. The arguments apply to demand increasing expenditures of any sort, except as will be clear from the text. 
Figure 1

(a)

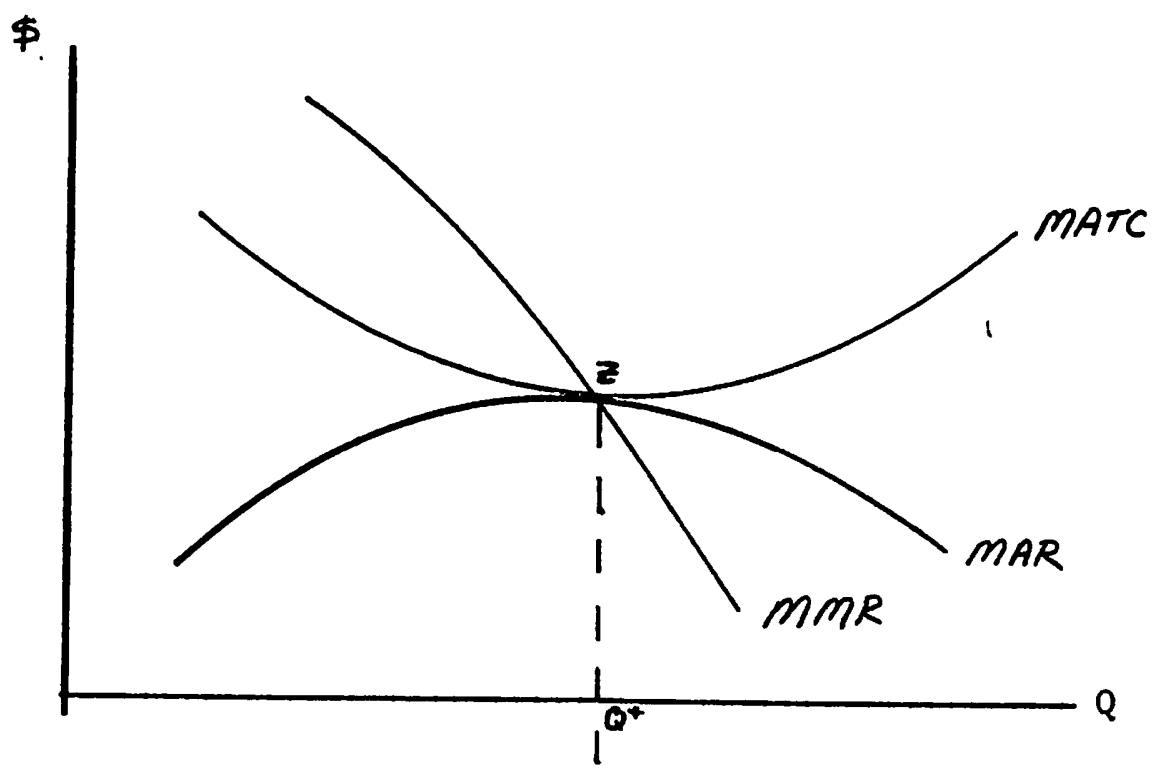

(b)

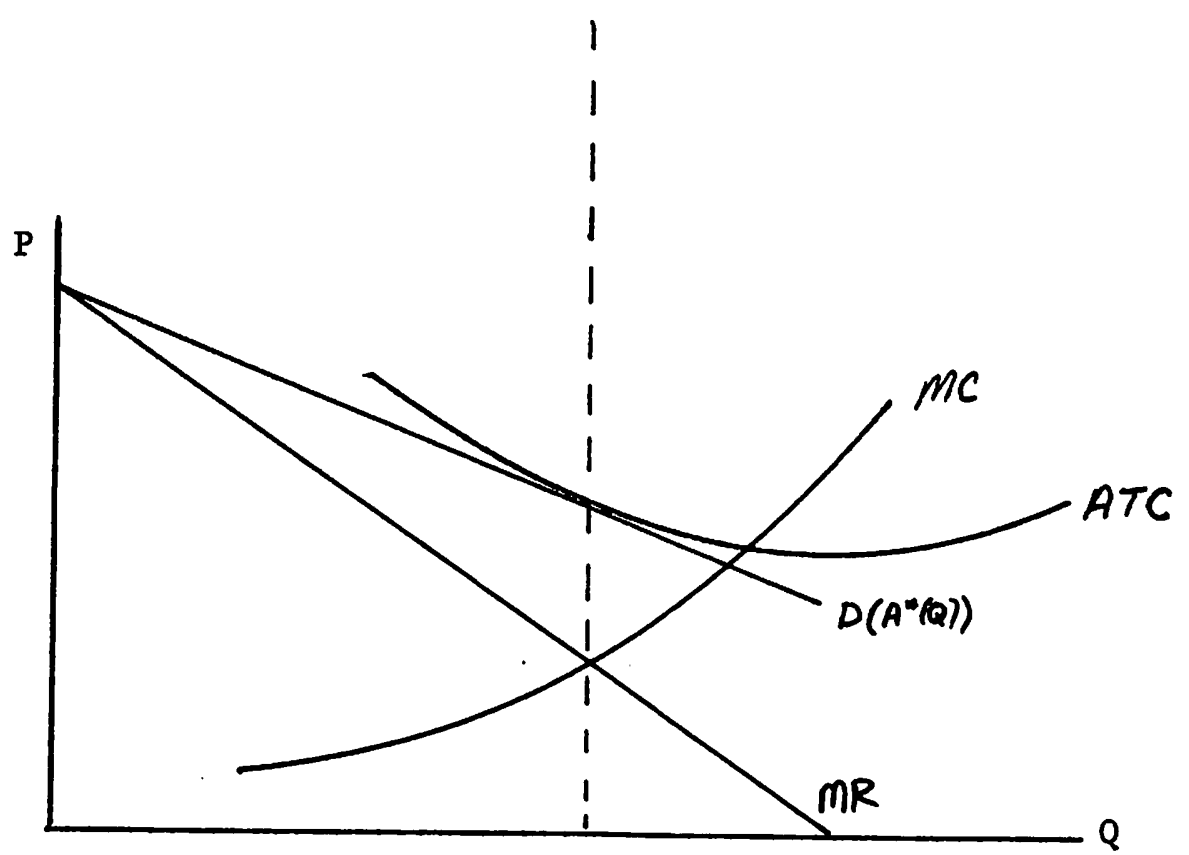


argues, the socially relevant average cost notion must include advertising, since the theoretical prejudgment that advertising is wasteful nearly settles the issue. It should be noted that the literature is not decisive on the social usefulness of advertising. In the diagram, the firm is shown to be operating at the minimum of average total cost, but such a result is not necessary. Tangencies could occur to the left or right of the tangency shown. However, Demsetz also considers possibilities of industry rationalization through various means such as subcontract, merger, spinoffs, etc., which could move firms in an industry toward the minimum point of the LRAC.

Barzel's criticism can be seen readily with the aid of Figures 1 (a) and $1(b)$. Consider what must be occurring along the instantaneously horizontal (or upward sloping) portion of the MAR. Consumers are accepting a larger quantity of the product at the same (higher) price. Confronted with that, we have two choices which are consistent with the law of demand. It may be that consumers are being increasingly misled by advertising as quantity is increased. If this is true, the normative usefulness of this whole apparatus fails immediately as mentioned above. Alternatively it may be that the quality being offered is increasing as quantity is increased, so that consumers are behaving in accordance with their self-interest at all points on the MAR. Such recognition of consumer rationality requires a broad definition of quality, so that products which are better understood, or which require less search on the part of consumers, are conceived as "better" products. ${ }^{3}$ Given that, production at the minimum of the mutatis mutandis

3 Since 1970, several authors have attempted to nullify Barzel's criticism. See Ohta [1977], Murphy [1978] and Greenhut [1975]. For a discussion of the see Margolis [1982]. 
average total cost curve is not efficient since the average cost of "quality adjusted" output would have to be falling at point $z$. Figure 1 (b) illustrates this further. For a unit of output with quality as produced at point $z$, we could construct a corresponding demand curve under the assumption that quality is fixed. That demand curve would be tangent to an average total cost curve which differs from the counterpart above in that selling expense is held constant. The average cost curve constructed in this way must be tangent, or the zero profits point identified above would not reflect a profit maximum. This shows excess capacity in the commodity chosen at point $z_{0}$

\section{CROSS-PRODUCT EFFECTS OF SELLING EFFORT}

The analysis which follows assigns a central role to interactions of promotional or selling activities across the products which a firm produces. Simply put, where two or more products are identifiably provided by the same firm, actions of the firm with respect to one of its products will affect the values which consumers place on the firmls other products. It is probably the absence rather than presence of interactions of promotional efforts which requires special justification. It is, however, possible to offer both deductive and empirical support for the notion that selling activities in one part of a firm will affect outcomes in another part of that firm.

The modeI of advertising presented by Klein and Leffler [1981] provides a very natural basis for the assertion of cross-product effects. In their formulation, consumers will forever boycott a firm which has 
breached an implicit contract regarding the quality of goods to be delivered. The presence in the firm of capital which may not be salvaged if the firm leaves the industry provides assurances that the firm will not cheat on the implicit contract that it makes. Advertising, investment in brand-specific industrial designs, and elaborate showrooms are all examples of this nonsalvageable, or brand name capital. The additional expenditures required to sustain brand name capital are, in Chamberlinian terms, selling expenses. The connection between brand name capital and cross product effects is that non-salvageable capital of the entire firm will be held hostage against cheating with respect to any of its operations. If a drug company, for example, is shown deliberately to have cut costs by reducing quality, consumers will then boycott all of that firm's products. Brand specific capital therefore does double duty when two products are paired under a brand name.

Obviously versions of brand identification other than Klein's and Leffler's will also support promotional interactions. Theirs is, however, a very specific and appealing model which admits of empirical evaluation. Other assumptions on which to base cross-product effects are the existence of word-of-mouth advertising, spillovers of broadcast signals or simply the occurrence of travel across geographic markets.

Direct empirical validation of the existence of cross-product effects can be found in the structure of firms. The most obvious is the predominance of multiproduct firms in industries with differentiated products. While it may be difficult to distinguish between selling interactions and economies 
of joint production in the classical sense, there is certainly a significant subset of firms for which fabrication activities for different products are independent. At the extreme are licensing operations in which there is little involvement of the licensor beyond quality control and monitoring of the contract.

Further evidence of the significance of the posited interactions may be found in the content of advertising messages. Many ads emphasize the existence of a family of products or the large size or scope of a firm. Some ads will stress the affiliation of a product with some other unusually presitgious, durable, economical or otherwise advanced product. Along similar lines, some firms will feature an elite product which is responsible for only a miniscule share of the firm's revenues. Promotion of prestige lines, or flagship products seems to be an important strategy for firms producing automobiles, computers, cameras, alcoholic beverages and home electronics among others. 
IV. BRAND EXTENSION WITH SYMMETRICAL CROSS-PRODUCT EFFECTS

Consider a simple case of products that are identical and for which the interactions of advertising are symmetric. Such a description might be a reasonable approximation for a product that is sold in separate geographic markets, but for which there are symmetric advertising spillovers. For example, a chain of hamburger restaurants (if we may be permitted to abstract from the complexities introduced by franchising relationships) or a chain of drug stores would fit this description fairly closely. We will assume that these outlets are sufficiently geographically separated so that they do not compete with each other in the usual sense. While the multi-brand retail operation fits most readily into this formulation, it is worth noting that a number of other types of firms may also fit this description. So, while the retail chain is a convenient example, the application of the ideas that follow is by no means confined to retail chains.

Assume a firm that produces two products that face identical demand and cost conditions and that are linked only by a symmetric effect of selling efforts across products. Also assume for any given level of selling expense, both downward sloping demand and U-shaped average total cost. Finally, following Demsetz, assume that selling activity experiences initially increasing and subsequently decreasing returns. This last assumption is reflected in the diagram, but is not central to the discussion which follows. For purposes of discussion, it will be convenient to designate arbitrarily one of the products as the primary product (Product 1) and the other as the companion product (Product 2). 
A possible configuration for an equilibrium in monopolistic competition under the se assumptions is shown in Figure 2. Other firms are, of course, free to enter and to produce similar pairs of products. Equilibrium would therefore consist of competition among a number of similar firms each engaging in pairs of activities.

The major features of Figure 2 are, by now, quite conventional, although the interpretion of these features may not be. Frame a shows the mutatis mutandis curves as in Demsetz, although average benefits (MAB) replaces average revenues (MAR) to reflect the fact that part of the return to selling one product is the effect on the net revenues of other products. Figure 1 (a) shows the firm at a cost-minimizing point in the Demsetz sense, although again that is not necessary for what follows.

The departure from previous formulations is shown in Frame b. This diagram shows the ceteris paribus demand curves which follow from the selling expense behavior which yields the profit-maximizing quantity in Frame a. Taking Barzel's criticism seriously, we recognize that we must test for efficiency for the particular product (quality) that is chosen: In Frame b, we see that the firm is earning zero profits, and that there is a tangency of the conventional average revenue curve and the ceteris paribus average total cost curve. ${ }^{4}$ This figure, or its mathematical equivalent, would normally prompt us to infer the existence of excess capacity in this industry'。

A second average cost curve, however, prompts us to conclude otherwise. The curve labelled AATC (for adjusted average total cost) shows the average of total costs, including advertising costs, less the benefit conferred by this activity on the companion product. Frame $c$ shows this benefit as

4 Here note the role of symmetry. If markets or products differ, zero profit for the firm need not involve a tangency for each product. 
12

Figure 2

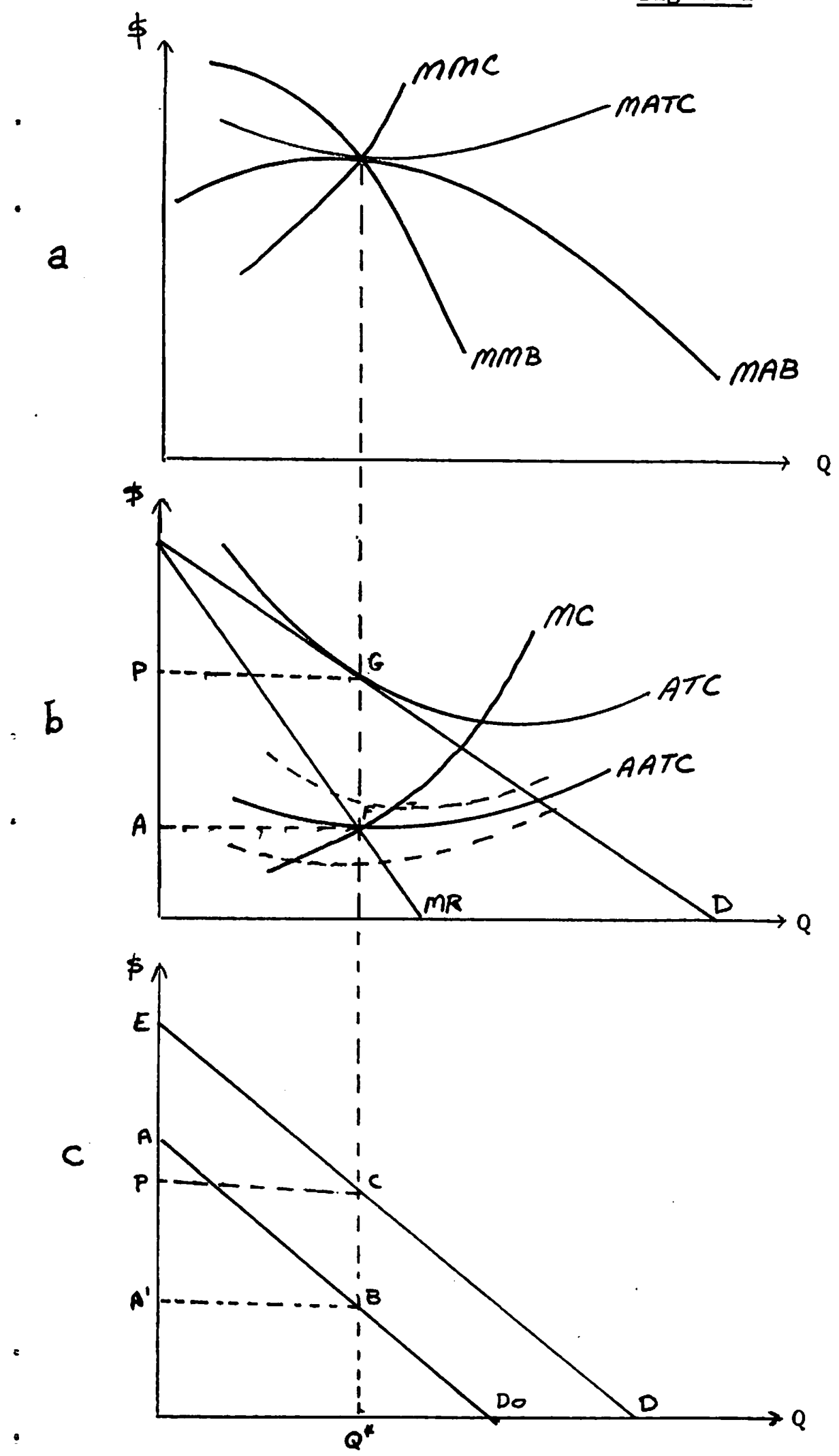

mutatis mutandis functions

ceteris paribus

(classical) functions

companion product classical curves 
a shift in the demand function of the companion product. In this symmetric use the representations of the two operations should be identical; for example, average cost curves as shown in Frame b belong to Frame $c$, but are omitted for clarity. For the moment, we interpret the benefit as the integral of the difference between the two demand curves up to $Q^{*}$. That area, designated the total cross effect (TCE), is the difference in total costs reflected in the two average total cost curves in Frame b (ATC, AATC). That is, area ABCE equals the area PAFG.

It is not a trivial matter to claim that the adjusted average total cost curve is the appropriate one to invoke in judging efficiency. That issue is taken up at length below. First, however, I should note that the calculation of the size of the cross effect is not trivial either. Under Under monopolistic competition, surplus computed from the perceived demand of individual firms cannot simply be added to get industry consumer surplus. This is most readily seen by considering the limiting case which is perfect competition. Areas under the firms' perceived demand are zero, yet the surplus for the industry need not be. Fortunately we are here dealing with changes in the consumer surplus, so that several transformations of the pairs of demand curves will result in no change in the benefit measure. Rotations of the demand curves $D_{0}$ and $D$ about the points $B$ and $C$, respectively, so that $D_{0}$ and $D$ remain parallel, will not alter parallelograms like $A B C E$. To see this, notice that the height of the parallelogram remains $Q Q^{*}$ while the base remains $\overline{\mathrm{BC}}$. For more general demand functions $\int_{0}^{Q^{*}}[F(Q)+C] d Q-\int_{0}^{Q^{*}} F(Q) d Q$ $=\int_{0}^{Q *} \mathrm{CdQ}=\mathrm{CQ*}$, so the area between vertically parallel demand functions will 
be invariant under transformations which preserve parallelism.' Note, also, that the benefit is equivalent to the effect on firms' revenues for selling Q*; i.e., the benefit equals A'BCP. For the case of identical individuals, the assumption of a parallel shift in the demand curves is equivalent to imposing a utility function of the form $U=U\left(Y, X_{i}, S_{i}\right)+X_{i} F\left(S_{j}\right)$ where $S_{i}$ is the promotion expense for differentiated products $i, j ; x_{i}$ is the consumption of the differentiated product and $Y$ is all other consumption. More directly and more generally, using parallel shifts imposes the assumption that all units consumed are identically affected by promotion of the companion product.

Although this case is offered in the spirit of a counterexample, the formulation employed so far does not hinge crucially on the particular benefit measure chosen. A slightly more general utility function, similar to that used by Dixit and Norman [1978], of the form $U=y+u_{1}\left(x_{1}, s_{1}, s_{2}\right)$ $+u_{2}\left(x_{2}, s_{1}, s_{2}\right)$ would yield a measure of the benefit in the consumption of product 1 from advertising in market two which equals $u_{1}\left(x_{1}, s_{1}, s_{2}\right)-u_{1}\left(x_{1}, s_{1}, 0\right)$. Employing such a measure would yield an equally satisfactory example. Before considering at length the various cost notions invoked in the diagrams, it may be clarifying--or at least persuasive--to consider briefly an algebraic presentation which is equivalent to the diagrammatic treatment presented above. Preserving the symmetry of the example we assume identical demand functions $P_{i}=P_{i}\left(Q_{i}, A_{1}, A_{2}\right)$ where $P_{i}, Q_{i}$ and $A_{i}$ are, respectively, price, quantity, and advertising associated with the $i^{\text {th }}$ product (market). Total costs of the firm can be written $C_{1}\left(Q_{1}\right)+C_{2}\left(Q_{2}\right)+A_{1}+A_{2}$. For the symmetric case it is also true that $C_{1}(Q)=C_{2}(Q)$ for all $Q$. Then we have the firm's problem as 
(1)

$$
\underset{Q_{1}, Q_{2}, A_{1}, A_{2}}{\max }=P_{1}\left(Q_{1}, A_{1}, A_{2}\right) Q_{1}+P_{2}\left(Q_{2}, A_{1}, A_{2}\right) Q_{2}-C_{1}\left(Q_{1}\right)-C_{2}\left(Q_{2}\right)-A_{1}-A_{2}
$$

which yields the necessary conditions:

$$
\begin{aligned}
& \frac{\partial \pi}{\partial Q_{1}}=\frac{\partial P_{1}}{\partial Q_{1}} Q_{1}+P_{1}\left(Q_{1}, A_{1}, A_{2}\right)-C_{1}^{\prime}\left(Q_{1}\right)=0 \\
& \frac{\partial \pi}{\partial Q_{2}}=\frac{\partial P_{2}}{\partial Q_{2}} Q_{2}+P_{2}\left(Q_{2}, A_{1}, A_{2}\right)-C_{2}^{\prime}\left(Q_{2}\right)=0 \\
& \frac{\partial \pi}{\partial A_{1}}=\frac{\partial P_{1}}{\partial A_{1}} Q_{1}+\frac{\partial P_{2}}{\partial A_{1}} Q_{2}-1=0 \\
& \frac{\partial \pi}{\partial A_{2}}=\frac{\partial P_{2}}{\partial A_{2}} Q_{2}+\frac{\partial P_{1}}{\partial A_{2}} Q_{1}-1=0
\end{aligned}
$$

For a long-run (full entry) monopolistically competitive equilibrium we have an additional condition that profits equal zero.

A concern in this investigation is, of course, average costs. In the usual case of a multiproduct firm, there is no natural definition of average cost. In this setting there are actually two distinct definitions of average cost which are useful, but the two are equivalent given the current symmetry assumption. The first candidate is $\left[C Q_{i}+A_{i}\right] / Q_{i} \cdot$ This is the cost generated directly in connection with producing and selling good $i$ divided by the quantity of $i$. Consideration of rates of change in this average cost measure are fairly natural: we should consider the change in the average cost of $i$ with respect to $Q_{i}$. The availability or sensibility of this concept follows from the fact that the nature of the interaction in production is quite explicit here, so that the effect on product j's production of the pairing 
with product $i$ can be taken account of explicitly. The interaction is the total cross effect (TCE) where $T C E=Q_{j} P_{j}\left[Q_{j}, A_{i}, A_{j}\right]-Q_{j} P_{j}\left[Q_{j}, 0, A_{j}\right]$.

An alternative computation of average cost that is available where units can be sensibly aggregated is the total of all costs to the firm divided by the sum of outputs. For the general case, changes in average cost must be addressed in terms of changes along a ray in the output space; i.e., equal proportional changes in all of the outputs. For the present symmetric case, such a constraint (to changes along a ray) is the natural or obvious one; and with that the two average cost computations are equivalent, since averaging all costs over all outputs merely involves mitiplying the numerator and denominator of the product-specific average cost by two. (This choice of an expression for average total cost should not be confused with the more substantive question of whether adjusted or unadjusted average cost should be used in making efficiency judgments. This second issue is taken up below.)

We may now write classical average cost as:

$$
\operatorname{ATC}_{i}=\frac{C_{i}\left(Q_{i}\right)+A_{i}}{Q_{i}}
$$

and adjusted average cost is written

$$
\operatorname{AATC}=\frac{C_{i}\left(Q_{i}\right)+A_{i}-T C E}{Q_{i}}
$$

5

See Baumol, Bailey and Willig, "Weak Invisible Hand Theorems on the Sustainability of Multiproduct Natural Monopoly," American Economic Review, June 1977, p. 354. 
It will be argued below that our interest in investigating excess capacity is the behavior of the AATC curve. To have AATC at a minimum we require

$$
\frac{c_{i}^{\prime}\left(Q_{i}\right)}{Q_{i}}-\frac{c_{i}\left(Q_{i}\right)+A_{i}-T C E}{Q_{i}^{2}}=0
$$

or equivalently this requires only that

$$
C_{i}^{\prime}(Q)=\frac{C_{i}(Q)+A-T C E}{Q_{i}}
$$

It can be seen readily that this poses no conflict with the first order or zero profit conditions. The free parameters which assure that the counterexample may be constructed are prices in the zero profit condition and the elasticities of demand in the first-order condition. This is the mathematical equivalent of being able both to rotate and to displace vertically the demand function in order to achieve the intersections shown in Figure $1(\mathrm{~b})$. Thus an equilibrium may occur at the minimum of adjusted average total cost while still satisfying the first-order conditions listed above.

In Figure 2, the curve labelled AATC is drawn in such a way that the firm is shown to be operating at the minimum point on the curve. This of course need not be the case: the dashed, unlabelled curves are also valid candidates. The solid curve does demonstrate that the firm can operate at the minimum of average cost, so defined. If this average cost notion is accepted as the socially relevant one, we have demonstrated the possibility of efficient production, and so an exception to the 
so-called excess capacity theorem. Efficient production is only shown to be a possibility; it is not inevitable. The possibility of rationalization toward efficient production from other equilibria is considered in Section V.

Our task remaining is to establish that AATC is the socially relevant cost curve from which to judge the efficiency of the market organization. In order to consider this issue, we must digress momentarily to consider why we treat average cost as a relevant measure at all (some might prefer simply to damn monopolistic competition for the divergence between marginal cost and price). The excess capacity result of monopolistic competition is deemed to be important because the total cost incurred by all of the firms in a market is too large. A regulator with perfect information could eliminate some firms, and reallocate production to others, so that each firm operated at lower average total cost. Of course, this focus imposes the assumption that variety is not of any value to consumers.

Now consider the options available to our omniscient Chamberlinian in confronting the multiproduct brand name. One option is to intervene to eliminate a single operation (branch or product). Eliminating the operation has two offsetting effects. The fixed or start-up costs of an individual operation are avoided, so that remaining firms operate at lower points on their unadjusted average total cost curves. Also lost, however, will be the benefits through cross effects which had been accruing to the other operations under the brand name. For the case of the solid AATC (Figure 2) curve these are exactly offsetting, so that no social benefit is achieved. The reduction in cost is offset by the loss of product enhancement elsewhere in the economy. 
The second option that might be contemplated is the elimination of an entire firm, that is, all of the branches or products produced under a particular brand name. As in the traditional model, remaining firms could be moved down their unadjusted average total cost curves, so that a given quantity is produced at lower total cost.

The appeal of eliminating entire firms will hinge crucially on our view of the way in which promotional efforts operate to shift the demand facing an individual firm.

One traditional view of advertising is that it consists of many cross-cancelling messages. Alternatively, it may be that advertising consists of messages which have no function other than to inform the consumer of the existence of a redundant choice. In either of these cases, an argument could be made that Figure 2 presents a picture of excess capacity. Consider the case of the successful communication of a true message: "Our tools are reliable." That message may certainly be of some value to a consumer. However, if this signal is successfully communicated (presumably through the same techniques) by each of five manufacturers that make tools, and elimination of one firm merely switches customers to other firms also established to be reliable, it would be difficult to find that the cross effects should be treated as social benefits which perish with elimination of that firm. Cross effects within the eliminated firm were enhancing the real value of its product, but were also reducing the real value of correct information about other firms.

Other interpretations are, a priori, equally appealing. It may be that increases in the total number of messages will increase the probability that any given consumer will receive the message even once. The "quality constant" assumption which is imposed on the quantity dimension in Frames b 
of Figures 1 and 2 may refer to the ease of acquiring information about that particular firm. Such a construction does not require that the ease of acquiring information about the product class as a whole is unchanging along the quantity axis. More firms, and therefore more total advertising, may in some cases mean that more consumers are aware of the very existence of the class of products. Still another possibility, albeit one closely related to the more standard concern over variety per se, is that different styles of promotion, advertising, salesmanship, etc. appeal to different con sumers.

The issue needn't hinge on such metaphysics alone; some empirics may be quite persuasive. Should we find that an increase in the number of firms in an industry, together with the associated change in total industry selling effort, increases aggregate demand, we would have to reject the hypothesis that the advertising of the marginal firm is inconsequential. We are then faced again with the very loaded question mentioned at the outset; are consumers duped or served by these selling efforts?

So long as we refrain from condemning advertising and therefore prejudging the case, the option of eliminating entire firms will not be, in general, welfare-improving. Unadjusted average total cost will be lower, but the savings is accompanied by a reduction in the total amount of selling effort pertaining to the products involved.

Another possible move for our perfectly informed interventionist is recombination of products into brand names. This may be disposed of rather briefly on two grounds. First, it is questionable whether any such useful recombination of products would not be accomplished by private markets. 
Second, it would seem that the signal offered by association might differ according to whether the association were voluntary or coerced. Thus, if I knew that a firm sells a particular product only because the firm was compelled to do so, I might hesitate to draw the conclusion that the firm's reputation for quality could be extended to this product.

It is instructive at this point to consider why the implications of interactions of promotional activity differ from the implications of other economies of joint production. Let us consider what would happen if we changed the example to reflect an economy in central office expense. We will ignore advertising but otherwise not change the example, so that we still have two products facing identical demand and cost conditions. Figure 2(c) has no analogous role in the analysis, and the ATC in 2(b) reflects diminished costs due to joint production. (Again the symmetry of the example must be invoked to justify the definition of average cost.) Adjusted average total cost is ATC less the cost savings in the companion product. The total savings from pairing the products is 2AFGP. Why isn't AATC again the socially relevant average total cost curve? The answer is that a rearrangement of production which reduced the number of firms (pairs) would move us down the ATC curve with no compensating reduction in anything that is valued by consumers. Therefore, as in the original Chamberlin model, excess capacity exists in the sense that an omiscient dictator could improve on market allocations. (Unless, of course, variety per se is held to be of value.) 
Some counterexamples are like eggs standing on end. Any minor change of the chosen values of parameters will alter the implications so completely that the conventional outcome is restored. Such examples are mostly of nuisance value and properly require only minor technical adjustments in our point of view. However, in the present case, while it is absolutely true that efficient production (minimum AATC) is exactly achieved only for the specific value of the cross effect such that $M C=A C-\frac{T C E}{Q}$, it is also true that cross effects "close" to the one required for the counterexample will yield outcomes arbitrarily close to the minimum of the relevant average cost curve.

This counterexample is also instructive in another sense. It is an accepted result in the monopolistic competition literature that the inefficient consequences of monopolistic competition increase, ceteris paribus, with the extent of product differentiation. The less elastic the firms' perceived demand curves, the greater the extent of excess capacity. However, in the framework employed here, there is no necessary association of the steepness of the demand curve and magnitude of the excess capacity. It seems plausible, in fact, that where effects like brand loyalty lead to steep firm demand curves, cross effects would also be quite large. Depending upon the magnitude of the cross-product effect of selling expense, a differentiated product could be produced under conditions of decreasing, increasing or constant average costs. 
V. RATIONALIZATION

With the exception of Dewey [1958] and Demsetz, theoretical economists have had fairly little to say about rationalization of industry. Demsetz' discussion is more of a sketch than a detailed treatment. Having demonstrated that average cost minimization is possible, it was fairly natural, given his model, for Demsetz to assume that it was sought. Demsetz therefore merely suggests some of the avenues that might be employed which would have the effect of moving the industry toward the minimum average cost set of outputs.

There are a number of reasons that rationalization is a forbidding topic. First of all, the kinds of arrangements which could be tried by firms are limited only by entrepreneurial imagination. Second, with only limited exceptions, the entire production literature assumes that the production function is exogenous. Exploration of rationalization thus breaks new ground in a very important way. Finally, it is a fairly compelling simplification to assert that the production function, as characterized in theory, reflects full exploitation of the possibilities for rationalization. This last stipulation is formally valid but it denies any possibility of explaining a large number of transactions which occur among firms. Further, full application of this simplification requires that we have more complete empirical grounding for the restrictions placed on production functions than can be legitimately claimed.

In the context of brand extension, analysis of rationalization is somewhat more demanding than it is in the case that Demsetz analyzes. In the present setting, it is not true that all profitable realignments will 
necessarily move the firm toward the minimum point of long-run average cost. So, while rationalization demands a complete analysis, that must await further writing. The comments presented below must be taken as an organizing framework or a research proposal.

There are three avenues by which firms experiencing excess or insufficient capacity might rationalize their activities. The first and simplest is selling to or buying from other firms so as to operate at minimum average cost. The second possibility, which economists may be ill-equipped to analyze, is changing the content of advertising or other marketing strategies so as to modify the extent of spillovers from one product to another. A third avenue, for which analysis seems difficult but promising, is acquiring additional companion products. I consider each of these in turn.

The first type of rationalization, which is also discussed in Demsetz, is readily associated with common phenomena. Producers with excess capacity are known to contract to produce output for sale under another brand name such as a department store or distributor "house brand". Firms which experience insufficient capacity will contract for production of branded goods or may license production of protected designs. The analytics of this kind of behavior are fairly simple.

With reference to Figure 3 , let $\tilde{Q}$ be the output at which a minimum is obtained for average total cost less the cross-product effect. It is clear that a firm operating to the left of $\tilde{Q}$, as is the case for the firm shown in the diagram, would be willing to sell output to another marketing organization at a price above $\overline{M C}$. Similarly, firms operating to the right 


\section{Figure 3}

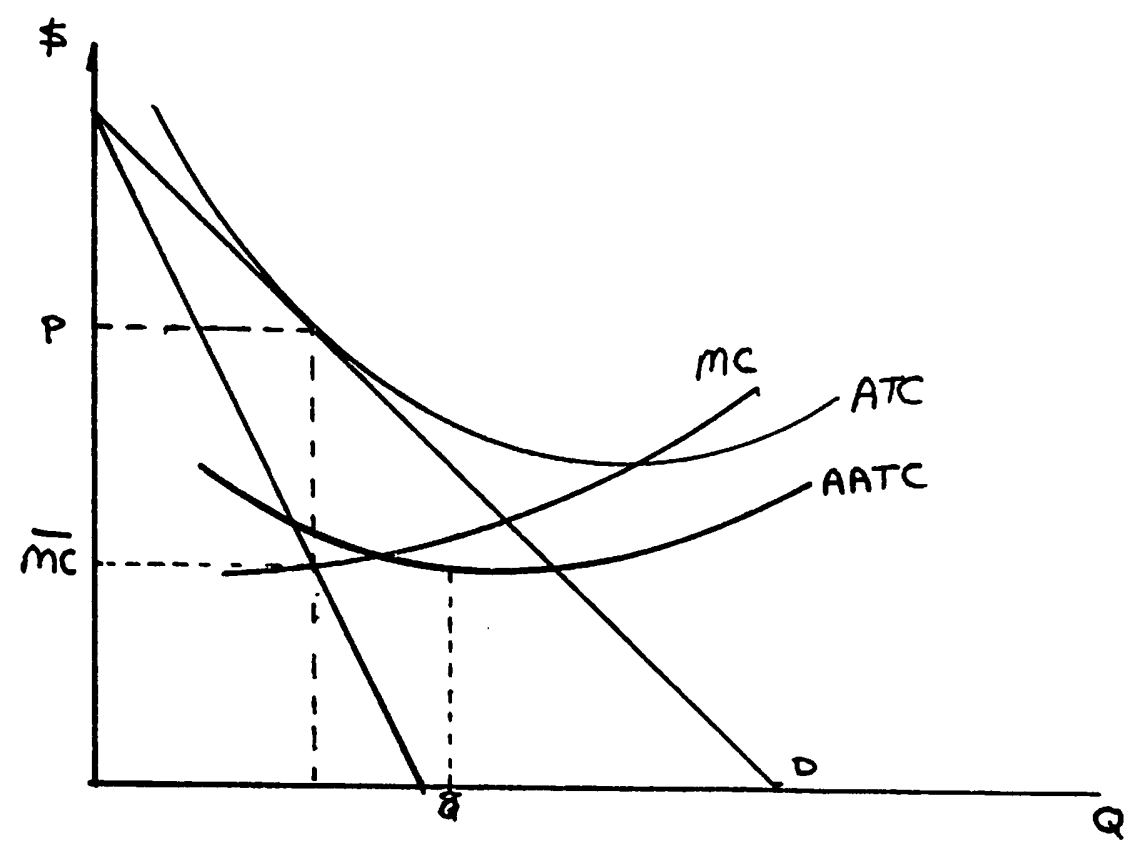

of $\tilde{Q}$ are buyers at prices below some $M C^{\prime}$ such that $M C^{\prime}>M C(\tilde{Q})$. With this, the equilibrium price for inter-firm transfers of goods is $M C(\widetilde{Q})$ and firms operating at levels of average total cost which are above $M C(\tilde{Q})$ are making losses if firms operating at minimum adjusted average total cost are breaking even.

A reasonable objection to this analysis is that the introduction of buying and selling is either a change in the technology of production or a departure from the essence of monopolistic competition. One might argue that if buying and selling between firms is permitted, then the initial representation of the average cost curve as $U$-shaped was faulty and that average cost is actually a constant. Alternatively, it might be argued that this representation diminishes the role of product differentiation to insignificance, since the differentiated aspect is being treated as 
something which is readily added on or taken off with the transfer of goods between firms.

In spite of these concerns, this kind of rationalization is important for several reasons. First, it suggests that the assumption of U-shaped cost curves may be treacherous if we are to insist that production possibilities include purchase of completed or partially completed goods from outside the firm. Also, it demonstrates that excess capacity is readily averted if the differentiating aspects of production can be separated from the undifferentiated part. Since economists' attention to monopolistic competition seems to follow largely from the intuitive appeal of product differentiation, this last point is especially important. What is required to make the excess capacity theorem stick is not only the assumption of product differentiation, but also some restrictions on technology which are far less compelling than product differentiation. The existence of brand names which are supplied entirely by purchases from other manufacturers, the sales between manufacturers of major components, and the practice of subcontracting for entire lines of goods are phenomena which call into question the restrictions on technology which support the traditional mode1.

Alterations in advertising messages so as to emphasize or de-emphasize the larger family of products is a second avenue of rationalization. The constructs of the previous sections do not allow for analysis of this type of adjustment since, in the symmetric case, messages which maximize the total effect are always chosen. However, it at least bears mentioning that the 
extent of interaction across products might be more properly modeled as endogenous in some cases.

The third avenue for rationalization seems both the most difficult and the most promising. By assembling additional products under a single brand name, the firm creates additional benefits for its marketing activity. Notice that such brand extension may involve movements of, as well as movements along, the socially relevant average cost curve. For this reason, it cannot be said that all rationalization moves the industry toward the minimum of adjusted average total cost. It seems likely that acquisitions which lead to increased outputs for existing products would be most attractive to firms currently experiencing excess capacity, ceteris paribus. However, holding all other things constant may make fairly little sense in this case, since a particular "brand extending" product might be attractive to two or more firms in entirely different industries.

A complete theory of product line choice is likely to be elusive. The returns to such a theory may, however, be quite large. An understanding of how equilibrium configurations of products are obtained may go a long way toward explaining phenomena such as conglomerate mergers. Many assemblies of activities heretofore regarded as suspect on efficiency grounds, may in fact represent efficient exploitation of brand name which may in turn yield favorable outcomes regarding utilization of capacity. 


\section{IMPLICATIONS}

The foregoing has two sorts of implications. At a very general level, it raises issues about the applicability of the monopolistic competition model as a basis for public policy. At a more specific level, it has implications regarding the treatment of product-differentiating measures in antitrust and intellectual property law.

An early critique of monopolistic competition by Alfred Sherrard [1951] motivates the more general implications. Brazenly abstracted, Sherrard's argument is that the scientific success of the Marshallian model of competition is the consequence of very fortunate choices of simplification, i.e., suppression of the details of real world phenomena. Sherrard argues that Chamberlin fails because he abandons the Marshallian abstractions without substituting new simplifications sufficient to yield a coherent or useful theory. Sherrard notes further that the urge to modify the Marshallian assumptions follows from a change in the relative importance of business activity away from buying and fabricating and toward selling. However, he notes that correct treatment of selling is not readily accommodated within the philosophical foundations of economics. Only a fundamental change in approach will permit economists to deal with the new circumstances, but in the meantime, the partway measures of the Chamberlin model are doomed to failure.

While Sherrard's call for fundamental change may exhibit unwarranted pessimism, his focus on the role of restrictive assumptions is instructive. The survival of the monopolistic competition model in textbooks and in the scholarly 1iterature rests largely in the intuitive appeal of the assumptions, at least as compared to the restrictions imposed by the economic model of competition. Yet it is precisely the restrictive nature of the assumptions 
of the competitive model which results in the empirical implications of competition. Without further restriction, the model of monopolistic competition as presented in Chamberlin is without empirical implications [q.v. Archibald 1961].

Whatever the merits of scholastic involvement with models for which the appeal rests in the realism of their assumptions, there are unrecognized dangers in applying such models to public policy. This paper illustrates one example of that danger. The Chamberlin model, by introducing more realism as compared with perfect competition, generates the implication of a tradeoff between variety and cost. The discussion here shows that a bit more realism will in turn destroy that result. Without a set of distinguishing implications and a body of literature to test those implications, there is no basis for choosing between these two models as a basis for policy. While it is doubtful that policies have been based on specific constructions of the Chamberlin model, it does seem that monopolistic competition is the view of economic reality which underlies many policy discussions. Policies which aim to foster greater exploitation of economies to scale are but one illustration of this. Advocacy of empirically unsupported or unsupportable models is a fairly widespread problem, not limited to monopolistic competition. A recent paper by Schmalensee [1979] provides a clear example. In an article titled "On The Use of Economic Models in Antitrust..." he says, "If enough data of the right sort are available, or if controlled experimentation is possible, at least in principle, one can select the best among a set of competing models entirely on the basis of the accuracy of their predictions. In the analysis of individual markets or business practices, this may not always be possible, 
however, because several models may have predictions consistent with the evidence available. In such cases one has little choice but to look at the assumptions on which competing models rest." [p. 995] The objection to Schmalensee should be clear. Models which depart from competition, or any other empirically supported candidate, in their normative but not positive implications cannot be held to have superior standing for policymaking on the basis of having more realistic assumptions. It is generally held to be possible to make up several stories that will fit a given set of facts. The exercise is even easier when there are no facts. Untested or untestable theories may well deserve further examination by academics, but as guides to public policy they belong in the same category as wild guesses.

Given the position taken above, specific and positive policy prescriptions should not be expected and what follows is mostly negative. It is possible, however, to offer suggestions regarding issues on which notions about monopolistic competition appear to have influenced policy. The most direct implication for policy pertains to mergers of various sorts. Antitrust policy has tended to regard true conglomerate mergers as benign while attacking horizontal mergers in concentrated industries. Mergers which involve products that are related, though arguably not directly in competition, have been an uneasy spot in antitrust policy. An implication of this paper is that such alliances may allow for efficient exploitation of a brand name, and may in addition mitigate excess capacity problems which might have occurred as a consequence of product differentiation.

In academic writing, brand proliferation has recently become a popular concern. According to this theory, a firm may produce a large number of differentiated but related products in order to deter entry. This argument has now made its way into the leading introductory economics textbook in Canada 
[Lipsey, Purvis, Sparks, Steiner, 1982, p. 303] and has been the basis of antitrust action in the U.S. The foregoing presents one alternative explanation for the success of multiple product firms. While the occurrence of what has been called brand proliferation does demand explanation, the entry deterrence argument, and for that matter the argument presented here, must be regarded for the time being as interesting conjectures. For the reasons mentioned above, they have no standing as a basis for policy. Further, the analysis of this paper implies that even if brand proliferation does have the consequence of deterring entry, the benefits of cross products effects may well outweigh any social losses which might result from this barrier.

The most direct implications of the preceeding pertain to social policies toward brand names, trade marks and industrial designs. Since Chamberlin, differentiating measures have been under some suspicion, although in practical discussion most economists would probably concede the worth of various types of firm identification. A fairly standard treatment speaks of a tradeoff between the information benefit versus the costs of monopoly power arising from trademarks and advertising [e.g. Scherer 1971, pp. 330-331]. As has been argued above, that tradeoff may not exist. Instead, by facilitating the measures which firms may use to exploit their reputations, brand name protection may diminish rather than increase the costs associated with product differentiation.

Trademark, brand name and industrial design law has not been an area for active legislative or judicial reform. However, these property rights have long been argued to introduce barriers to entry, and recent writings have given renewed Iife to this view [e.g., Spence 1980]. There is some evidence that this academic concern has begun to have some influence on policy. An example 
is the F.T.C. action in the ReaLemon case in which it was argued by the F.T.C. that ReaLemon's brand name constituted a barrier to entry. The argument and initial finding focuses on a predatory pricing argument, although the pricing practices used by ReaLemon would probably not have been viewed as predatory by the usual standards used in such cases. ReaLemon's price was not below average cost of the new entrant, however, the F.T.C. argued, and administrative law judge Lee Hanscom held, that ReaLemon's superior brand name would have made it necessary for the entrant to price below its average cost in order to compete. A significant aspect of the case is the remedy employed; ReaLemon was required to license its brand name and associated trademarks at a price equal to administrative cost. Since confiscation of specific productive assets of a defendent is not a common sort of remedy, the decision suggests that the brand name does not enjoy the same status as other property rights. Further the remedy seems to ignore the reasoning that has been put forward to explain why consumers might rationally choose to purchase well known brand names. 6 Chamberlin himself argues that trademark and brand name protection is equivalent to patent. He argues that both forms of protection spur innovation, but at the cost of introducing monopoly power. Chamberlin concludes that trademark protection should be weaker than it is and that it should be allowed to erode. Legal treatment and even popular discussion seems to be ahead of economic theory in recognizing that the brand name provides a continuing prod to desirable behavior on the part of the brand name owner in a way that patent

${ }^{6}$ Given the concerns expressed here with the function of a brand name as providing assurances of quality, the most interesting aspect of the Realemon case appears as a footnote to the administrative law judge's opinion. In considering what ReaLemon perceived Golden Crown's costs to be, it was noted that Golden Crown's ingredients were adulterated and that ReaLemon personell knew this. Golden Crown used citric acid and sugar instead of lemon juice but did not reveal this to consumers. This was noted only for its bearing on perceptions of cost. The contrast between ReaLemon's and Golden Crown's behavior is an ideal illustration of the quality assurance function of a brand name. If this prompted any concerns about the consequences of weakening brand name protection, they were not noted in the opinion. 
protection does not. This paper makes the further point that Chamberlin's claimed effects from the monopoly power are uncertain, reinforcing the argument against his proposed weakening of trademark, brand name and related protection. 
REFERENCES

Archibald, G. C., "Chamberlin Versus Chicago," Review of Economic Studies, October 1961, : 2-28.

Barzel, Y., "Excess Capacity in Monopolistic Competition," Journal of Political Economy, September/October 1970, 78: 1142-49.

Baumol, W. J., Bailey, and R. D. Willig, "Weak Invisible Hand Theorems on the Sustainability of Multiproduct Firms," American Economic Review, June 1977, 67: 354-65.

Chamberlin, E. H., The Theory of Monopolistic Competition (eighth Edition) Cambridge, 1962.

Demsetz, H., "The Nature of Equilibrium in Monopolistic Competition," Journal of Political Economy, February 1959, 67: 21-30. , "The Welfare and Empirical Effects of Monopolistic Competition," Economic Journal, September 1964, 74 :

_, "Do Competition and Monopolistic Competition Differ?" Journal of Political Economy, February 1968, $76: 146-48$.

Dewey, D., The Theory of Imperfect Competition: A Radical Reconstruction, New York, 1969.

Dixit, A. and V. Norman, "Advertising and Welfare," Bell Journal of Economics, Spring 1978, 9: 1-17. , and Stiglitz, "Monopolistic Competition and Optimal Product Diversity," American Economic Review, June 1977, 67 : 298-308. Federal Trade Commission, "In The Matter of Bordon Inc." Federal Trade Commission Decisions 92 (July-Dec., 1978), Washington, U.S.G.P.0. Greenhut, M. C., A Theory of the Firm in Economic Space, Austin, 1974. Klein, B. and Leffler, K. B., 'The Role of Market Forces in Assuring Contractual Performance," Journal of Political Economy, April 1981, 89: 615-41. 
Lipsey, R. G., Purvis, D. D., Sparks, G. R., Steiner, P. 0., Economics (fourth edition) New York, 1982.

Margolis, S. E., Barzel Versus Demsetz: A Review of Recent Criticism, unpublished working paper, University of Western Ontario.

Murphy, M., "The Consistency of Perfect and Monopolistic Competition," Economic Inquiry, January 1978, 16 : 108-12.

Ohta, H., "On the Excess Capacity Controversy," Economic Inquiry, April 1977, 15: $153-65$.

Pauly, M. V. and M. A. Saterthwaite, "The Pricing of Primary Care Physician's Services: A Test of the Role of Consumer Information," Be11 Journal of Economics, Autumn 1981, 12 : 488-506.

Salop, S. C., "Monopolistic Competition with Outside Goods," Bell Journal of Economics, Spring 1979, 10: 141-56.

Scherer, R. M., Industrial Market Structure and Economic Performance, Chicago, 1971.

Schmalensee, R., "On the Use of Economic Models in Antitrust: The ReaLemon Case," University of Pennsylvania Law Review, 1979, 92: 992-1050.

Sherrard, A., "Advertising, Product Variation and the Limits of Economics," Journal of Political Economy, April 1951, 59: 126-42.

Spence, M., "Product Differentiation and Welfare," American Economic Review, May 1976, 66: 407-14.

Spence R. M., "Notes on Advertising, Economies of Scale and Entry Barriers," Quarterly Journal of Economics, 1980: 493-507.

Stigler, G. J., "Monopolistic Competition in Retrospect," in The Organization of Industry, Homewood, Illinois, 1968.

Tauber, E. M., "Brand Franchise Extension: New Product Benefits from Existing Brand Names," Business Horizons, March/April 1981, 24 : 36-41. 